\title{
Los Movimientos sociales en la Argentina: de los noventa a la actualidad. Origen, desarrollo y perspectivas
}

Saúl Luis Casas ${ }^{1}$

Recibido en marzo de 2015, aceptado en abril de 2015.

\begin{abstract}
Resumen
En este artículo se analizará el proceso que llevó a la formación de algunas organizaciones sociales emergentes a partir de los años 90 en la Argentina. Luego de la aplicación de una serie de medidas políticas y sociales de parte del gobierno de Carlos Saúl Menem durante el período 1989-1999. Se verá cómo se desarrollaron las primeras formas de protesta y resistencia a ese gobierno y la transformación que fueron operando en el período respecto a sus demandas y formas de acción colectiva. Se tratará de dar una explicación del papel cumplido por estas organizaciones en la coyuntura que derivó en la caída del gobierno de la Alianza (1999-2001). Más tarde se verá la situación de estos movimientos sociales en la transición hacia el gobierno de Néstor Kirchner a partir del año 2003 y el lugar actual que ocupan respecto del gobierno de Cristina Fernández. El trabajo se cierra con una reflexión sobre los alcances e implicancias actuales del accionar de estas organizaciones sociales en la Argentina.
\end{abstract}

Palabras claves:

Argentina, reformas estructurales, neoliberalismo movimientos sociales, kirchnerismo.

\begin{abstract}
:
This article describes the process that led to the formation of some social organizations emerging from the 90s in Argentina is analyzed. After implementing a series of political and social measures from the government of Carlos Saul Menem over the period 1989-1999. It will be seen how the earliest forms of protest and resistance to the government and the transformation that were operating in the period regarding their demands and forms of collective action were developed. It will be an
\end{abstract}

1.Profesor de Problemas de Historia Americana. Facultad de Humanidades y Ciencias de la Educación. Universidad Nacional de la Plata, Argentina. Email: casas.scasas@gmail.com 
explanation of the role played by these organizations in the situation that led to the fall of the government of the Alliance (1999-2001). Later the situation of these social movements in the transition to the government of Néstor Kirchner since 2003 and the current place of respect to the government of Cristina Fernandez will. The study ends with a reflection on the scope and implications of current actions of these social organizations in Argentina.

Keywords:

Argentina, structural reforms, neoliberalism, social movements, kirchnerismo.

\section{Argentina: Neoliberalismo y transformación estructural}

El origen de la profunda trasformación experimentada por la Argentina en las últimas décadas, es posible encontrarla en las modificaciones que se inician con la dictadura militar (1976-1983). Desde aquella época se vinieron experimentando cambios en la estructura productiva que se sostenía en el modelo de industrialización por sustitución de importaciones desde los años 30. El país con la dictadura experimentó un proceso de transformación de su matriz productiva y de esa forma se fue imponiendo un nuevo comportamiento económico-social basado en la valorización financiera y la apertura comercial. Esas trasformaciones afectaron todas las dimensiones de la vida social, porque desde ese momento y por primera vez, junto a la quiebra del régimen democrático se construye una realidad de libre mercado, que apuntó a superar la crisis del Estado de Bienestar que se inicia en los 70 , a través de la desindustrialización y el endeudamiento provocados. Es decir, se alteró la base productiva y también de manera notable la estructura de la sociedad.

Esta tendencia no pudo ser revertida en los años de la vuelta democrática a partir de 1983 y el gobierno de Ricardo Alfonsín (1983-1989) fue envuelto en una crisis muy profunda que derivó en el adelantamiento de la entrega del poder. Con la crisis de 1989, el Estado Benefactor se precipita a una de mayor envergadura, que únicamente puede ser resuelta sobre la base de las transformaciones estructurales, según el discurso neoliberal que se instala con fuerza en ese momento. Las crisis hiperinflacionarias de 1988 y 1989, significaron un momento clave, porque dieron la base para la toma de decisiones drásticas para resolver el problema estructural de la economía y la sociedad argentina.

El gobierno de Carlos Menen que asume a partir de octubre de 1989, al adquirir un consenso notable, logró llevar adelante un paquete de reformas fundamentales que constituyeron un modelo que descansó sobre tres pilares:

1) La Convertibilidad 2) La reinserción de la Argentina en el mercado internacional de capitales y 3) Las reformas estructurales (privatizaciones, ajuste fiscal, apertura comercial y liberalización financiera, descentralización, flexibilización 
laboral, reforma del sistema previsional) medidas que tomadas en forma de "shock", modificaron estructuralmente a la sociedad argentina.

Las políticas de reforma del estado y la consolidación definitiva de un nuevo régimen de acumulación terminan de quebrar la matriz estado-céntrica, desplazándose varias actividades públicas hacia el mercado y consolidándose un nuevo modelo de relaciones entre estado y sociedad.

A continuación se mencionan las implicancias sociales de este proceso de reformas, que afectó de manera notable la vida social, económica y política de la Argentina, generándose lo que algunos especialistas denominan como una crisis de socialización.

\section{Los costos sociales de la reforma estructural}

Se puede decir que los efectos de estas trasformaciones promovieron un haz diverso de cuestiones sociales y económicas las que pueden esquematizarse en cuatro grandes ejes:

a. Concentración de la propiedad, del capital y del ingreso nacional. Distribución regresiva del ingreso. Cambio en el vínculo entre desempeño económico y desempeño del empleo: los tramos de reactivación económica no tienen efecto sobre el empleo.

b. Empobrecimiento general de la mayoría de la población. Crecimiento explosivo de los índices de desocupación y deterioro de las condiciones de vida y trabajo: desempleo, subempleo y empleo precario crecieronpersistentemente.Vul nerabilidad,precariedad,inestabilidad, clandestinidad del trabajo y caída de las remuneraciones conocidas como "Flexibilización laboral". Cambios regresivos en la estructura social: polarización, segmentación, fragmentación y exclusión social.

c. Debilidad institucional y presupuestaria en materia de servicios públicos, políticas sociales y políticas activas de estímulo a la competitividad "real". Estado con déficit fiscal permanente y con pésimas prestaciones sociales. Reducción del gasto público en general y del social en particular: educación, salud, seguridad social. Deterioro de la calidad de las políticas sociales. Reducción del margen de acción fiscal para atender a grupos sociales, provincias, regiones. Sistema impositivo altamente regresivo. Alto nivel de corrupción.

d. Vulnerabilidad externa: sistema económico vulnerable a los cambios internacionales, con retiro de capitales invertidos frente a situaciones de desequilibrio (Ej.: Crisis mexicana) por tratarse de "capitales golondrina" -están mientras los negocios sean rentables y seguros- y también las exportaciones dependen de los precios internacionales (productos primarios). Fuerte dependencia y débil equilibrio dependiente del mercado financiero internacional: de él dependen préstamos y negociaciones de deuda $y$, en definitiva, todo el financiamiento -endeudamiento (cada 
vez más caro) externo-desequilibrio de la balanza comercial-. Recesión, desinversión, declinación del PBI y estancamiento económico en general. Desindustrialización y consolidación de un modelo de acumulación basado en la exportación de productos primarios.

Este esquema nos permite observar un aspecto que es necesario remarcar para el período estudiado: el deterioro de las políticas públicas, específicamente respecto a las aplicadas en el denominado gasto social. Este aspecto puede verificarse en el marco del ajuste sobre salud, vivienda, educación y seguridad social y el achicamiento de la capacidad del estado para garantizar el empleo. Esta orientación evidencia un claro desmantelamiento de los restos del Estado de Bienestar, donde se observa además un deterioro creciente de los servicios destinados a satisfacer las necesidades básicas, y sobre todo la reducción de los salarios, pese al crecimiento de la productividad, así también se genera la denominada precarización del trabajo y el aumento del desempleo que, como ya hemos aclarado, contrastan con la concentración del ingreso.

\section{La crisis del modelo y las consecuencias político sociales}

Aquí es necesario efectuar una evaluación general de las consecuencias sociales del modelo de los 90 que permitió la consolidación de un nuevo bloque de poder controlado por los grandes grupos económicos nacionales y el capital extranjero, que bajo la adhesión abierta a los postulados neoliberales, lograron imponer un nuevo modelo de dominación social, fuertemente excluyente de los sectores populares y de amplias franjas de la clase media.

El neoliberalismo fue el sustento ideológico donde se cimentó la tan mentada reforma del estado, cuyo instrumento más conocido fue la privatización de las empresas públicas y la desregulación de las actividades económicas, frente al papel anterior que asumía el Estado, como el control de precios y la intervención en los mercados. El rol del estado cambió de manera radical, porque perdió capacidad de control (incluso respecto a los servicios privatizados), entre otras consecuencias, que terminaron definiendo el traslado al mercado del rol de asignar recursos. Un estado constituido de esa forma se autoexcluyó de sus posibilidades (y deberes) de preservar los derechos ciudadanos y de responder a las demandas de la sociedad. Esto redundó en el cuestionamiento de la legitimidad del estado como garante del bien común y del papel mediador de los partidos políticos y de la clase política en general, lo que acrecentó el malestar de la sociedad hacia el sistema político y hacia la política misma, en lo que podría definirse como una clara crisis de representación política.

La exclusión en sus variadas manifestaciones define un proceso que bien puede ser calificado como de una profunda crisis de socialización, tal como ya se ha expresado. Ésta se manifiesta en la conformación de una nueva lógica de organización social, donde la privatización de lo político y la preeminencia de la economía divorciada de la ética del bien común se constituyen en los rasgos 
decisivos de la Argentina de los 90, caracterizada por la lógica de la exclusión social. Esta experiencia genera una sociedad fragmentada, basada en la premisa del "sálvese quién pueda".

Asociado a los cambios operados a nivel de la política interna, tenemos que incluir a la nueva estructuración del ámbito del trabajo, tendencia que se viene manifestando en el mundo desde la década de 1980 con el avance de la globalización. Las principales consecuencias han sido la exclusión social, la precarización laboral y la caída de los derechos sociales. A lo largo del reciente proceso de transformación de la economía y el Estado, se produjeron reformas en la legislación laboral que anularon garantías previamente existentes.

El sindicalismo fue llevado a posiciones defensivas que no pudieron evitar el deterioro de las condiciones de los trabajadores. En cambio ciertos privilegios han favorecido a algunos sectores de la dirigencia sindical, que ingresan en una forma de pacto implícito con el gobierno de Menem. El sindicalismo se adapta entonces a la modernización promovida por el Poder Ejecutivo. Si bien es necesario decir que un sector del sindicalismo resistió a la aplicación de la embestida neoliberal aunque fragmentariamente. De esa manera cabe recordar que ya en la segunda mitad de 1989 se suscitaron conflictos laborales en diferentes fábricas y en el sector público donde los trabajadores estatales como los docentes protagonizaron varias huelgas. La alineación de la conducción de la CGT con el menemismo y la centralidad que adquirió el conflicto en el sector público condujo al nacimiento en 1992 del Congreso de los Trabajadores Argentinos que luego se convertiría en la Central de los Trabajadores Argentinos. Esta nueva central es una muestra de la aparición de un sector sindical con autonomía respecto al Estado y los partidos políticos, incluso articulando su acción con los movimientos sociales. Por otra parte es de destacar el surgimiento de una corriente interna en la CGT, que no tenía una propuesta alternativa al modelo sindical, pero se separa del sector más alineado con el proyecto oficial del gobierno de Menem. Este nuevo sector conformó el Movimiento de Trabajadores Argentinos (MTA) liderado por el secretario general del sindicato de Camioneros Hugo Moyano.

Esta fractura en el sindicalismo tuvo sus consecuencias. Los sindicatos en su conjunto pierden capacidad de negociación y de confrontación, lo que permite la consolidación de nuevas formas organizativas que participan por afuera del sistema institucional para la canalización de demandas.

Surgieron en ese contexto nuevos movimientos sociales que fueron vehiculizando la protesta social (cortes de ruta, asalto a gobernaciones, entre otras), que a su vez han recibido una fuerte cobertura de los medios de comunicación. Las protestas así canalizadas son la muestra de la profundización de la crisis de representación, que se evidenció en la mayoría de las instituciones políticas y 
gremiales. Con una fuerte presencia de estos nuevos actores, que incluso toman decisiones en Asambleas, se ha podido observar la configuración (de hecho) de una forma novedosa de democracia directa.

\section{Los nuevos movimientos sociales: evolución y desarrollo}

En el sentido que lo veníamos expresando, a comienzos de los 90 , se produjeron las primeras reacciones a las medidas implementadas por el gobierno de Carlos Menem (1989 - 1999), sobre todo desde los trabajadores del Estado, afectados por el proceso de racionamiento de sus puestos de trabajo y desde el gremio docente (CTERA), en defensa de la educación pública. En esta primera etapa, la movilización social se caracterizó por constituir una primera forma de confrontación con el modelo instituido.

Para los autores que analizan el periodo, el alza de la conflictividad no tuvo, sin embargo, una dirección estratégica, mostrando contradicciones y fracturas entre los diferentes grupos. Pasados los primeros cuatro años del gobierno menemista que propició cierta estabilidad en precios, al bajar drásticamente los índices de la inflación y permitir la recuperación del consumo interno, la conflictividad social se fue acrecentando. Para 1995 se inicia un proceso de quiebre en el orden capitalista mundial con la denominada crisis del tequila, esto afecta a la Argentina que evidencia un aumento significativo de los índices de desocupación. Las consecuencias son el aumento considerable de la conflictividad social (huelgas y protestas frente a los planes de ajuste) pero también algunas novedosas formas de organización que se crean en ese contexto.

Según opina Héctor Palomino, podría afirmarse que el origen de estos nuevos movimientos sociales fue múltiple, destacándose el surgimiento de redes territoriales favorecidas por la vecindad y aglutinadas de manera casi excluyente por dos factores primordiales: la desocupación y el cierre de fábricas. Esto permitió que la acción común derivara en la búsqueda de alternativas para conservar las fuentes de trabajo.

Entre esas experiencias es de notar el surgimiento del movimiento de desocupados o piqueteros formado por trabajadores desocupados, que en principio reclamaron el reingreso al mercado de trabajo, cortando las calles y rutas. Este movimiento social tuvo su origen en la provincia de Neuquén, en las Jornadas de Cutral-Co entre julio de 1996 y Abril de 1997, donde desocupados y docentes cortaron la ruta y fueron violentamente reprimidos por la policía provincial, represión que le costó la vida a Teresa Rodríguez. Según Paula Klachko, estudiosa del tema, a partir de los conflictos de Cutral Có y Plaza Huincul comienzan a adquirir centralidad, algunas formas de acción colectiva que han dejado una fuerte impronta en la sociedad argentina particularmente como método de lucha social: El corte de rutas, donde confluyen trabajadores ocupados y desocupados, que toman decisiones en asambleas como una forma de "democracia directa" y nuevas experiencias de organización que adquieren 
cierta independencia de organizaciones políticas y sindicales tradicionales.

Otra de las alternativas en la lucha a lo largo de la década menemista dio origen al movimiento de fábricas recuperadas donde muchos trabajadores deciden ocupar el local cerrado por sus dueños y volverlo a poner en funcionamiento. Este novedoso estilo organizativo tuvo un primer inicio hacia 1995, buscando la autogestión, ante el inminente cierre de las empresas y la imposibilidad de reubicarse en el mercado laboral.

Respecto a este tema dice Silvia Rodríguez, que el movimiento se montó en base a tres ejes: 1- la ocupación de la fábrica, 2-la resistencia al desalojo y 3la posterior puesta en marcha de la producción, sobre la consigna de: ocupar - resistir- producir.

Los sindicatos, salvo excepciones, no tuvieron mayor participación en este movimiento, y en cierta forma quedaron al margen de las decisiones que los obreros organizados tomaban. Así las empresas recuperadas, comenzaron a extenderse y adquirieron diferentes formas jurídicas desde las sociedades anónimas, hasta las cooperativas, buscado establecer un nuevo marco jurídico que las contenga, frente a la inexistencia de estas experiencias en la historia social Argentina. Lo interesante de este movimiento, que aún en la actualidad sigue en vigencia, es que persigue una forma horizontal de organización y distribución de los beneficios entre los trabajadores y ha permitido la igualdad con todos los compañeros en base a un proyecto económico en común.

Al final del gobierno de Fernando de la Rúa (1999-2001) otra de las formas experimentadas de organización social fueron las asambleas barriales que se desarrollaron en diferentes barrios de algunas ciudades como Buenos Aires, Rosario o La Plata. Allí aparecieron estas Asambleas, que cómo un verdadero foro popular, discutían sobre situaciones puntuales del barrio hasta la política de la ciudad y su proyección en la política nacional. Fue importante el rol de los sectores medios en esos espacios, donde aparecieron objetivos tan diversos que fueron alimentando formas de democracia directa, desarrollándose un espíritu participativo que claramente ponía en tela de juicio el sistema de representación político y de alguna forma el régimen político en su conjunto que estaba basado en los mandatos electorales existentes; la consigna "que se vayan todos" fue la expresión más radical de esta tendencia. Quizás la mayor preocupación no eran las estrategias de supervivencia, más propia de los sectores populares, sino la necesidad de la transformación de los valores institucionales vigentes y la realización de acciones simbólicas contra la política y los dirigentes políticos en general.

En un trabajo de conjunto dirigido por Maristella Svampa se puede inferir que en el marco de esas nuevas movilizaciones sociales en Argentina, aparecen estas experiencias de las asambleas barriales como un espacio multidimensional. 
En primer lugar, dice este trabajo, se los puede ver como un espacio de organización y de deliberación que se piensa en ruptura con las formas tradicionales de representación política y en favor de otras formas de autoorganización de lo social, con aspiraciones a la horizontalidad y proclives al ejercicio de la acción directa.

En segundo lugar, dice Svampa, las asambleas expresan la emergencia disruptiva de un nuevo protagonismo, a la vez indisolublemente político y social, que quebró el fatalismo discursivo ideológico de los '90, devolviendo a los individuos la capacidad de devenir verdaderos actores de la vida pública; en definitiva, de convertirse en sujetos del propio destino, tanto individual como social. En esta dirección, las asambleas traían consigo la promesa de la creación de espacios de solidaridad y de confianza, a partir de los cuales (re)construir los lazos sociales, tan socavados y mercantilizados tras una década de neoliberalismo.

En tercer lugar, continúa Svampa, estas nuevas experiencias reposicionaron a las clases medias, sobre todo de la ciudad de Buenos Aires, en un lugar importante de la escena política.

En este contexto, después del 2001 y en algunos casos, comenzaron a darse una serie de vínculos tanto a nivel territorial, como político y de acción social, que permitieron que las empresas autogestionadas lograran articularse con las asambleas barriales y los movimientos piqueteros, con lo cual conformaron un frente de lucha más consistente, que logró mantener formas de funcionamiento y cierta coordinación. En el mes de julio del año 2001 a unos meses de la crisis de diciembre se intentó constituir un primer congreso piquetero, que buscaba establecer formas coordinadas de acción. Allí acordaron un pliego de reivindicaciones y un plan conjunto de acciones de protesta. Pero esos encuentros mostraron algunas grietas en el proceso de articulación con evidentes divisiones internas, mostrando cierta tendencia que ha puesto límites al trabajo unitario dentro del movimiento. Sin embargo, la actuación del movimiento piquetero siguió teniendo protagonismo en las luchas políticas y sociales, más allá de la caída del gobierno de De la Rúa en 2001 y del posterior interregno de Eduardo Duhalde, entre enero de 2002 y mayo de 2003.

En los 90 fueron apareciendo otro tipo de acciones sociales de protesta, que es necesario destacar y que en cierta forma se inscriben en el repertorio de enfrentamiento al modelo de dominación impuesto por el menemismo. Algunas de estas expresiones no tuvieron que ver con el campo del sector laboralproductivo. Una de ellas fueron las marchas del silencio frente a crímenes aberrantes sostenidos en la impunidad oficial, como el caso en Catamarca, frente al asesinato de la joven María Soledad Morales en el año 1990.

Entre estos movimientos de oposición al menemismo es posible decir que las organizaciones de derechos humanos que habían surgido en los años 
80 redoblaron sus esfuerzos, en base a la consigna de "juicio y castigo a los culpables" el movimiento de derechos humanos se enfrentó a las llamadas "leyes de impunidad" (La Ley de obediencia debida y la Ley de Punto Final) promovidas por el gobierno de Raúl Alfonsín y luego a los indultos a las juntas militares decretado por Carlos Menem. Una importante renovación promovió el movimiento cuando surgió la organización HIJOS hacia 1996 que agrupaba a los hijos de desaparecidos y asesinados por la dictadura. Adquiriendo mucha visibilidad sus acciones en el ámbito público a través de marchas y de la utilización del "escrache" como instrumento de repudio a represores. El surgimiento de HIJOS reactivó la lucha al politizar las demandas por derechos humanos y ampliar su horizonte de acción uniéndose a otros sectores, como el movimiento estudiantil, incluyendo demandas y acciones sobre problemáticas que afectaban especialmente a los jóvenes y niños frente a la represión policial y la vulnerabilidad social y al denominado "gatillo fácil”, así como, denunciando al sistema penitenciario y la vida de los internos en las cárceles.

\section{El movimiento social y la crisis de la hegemonía neoliberal}

El ciclo de la hegemonía neoliberal se comenzó a cerrar a partir de la agudización del conflicto social desde 1999. El gobierno de la Alianza UCR-FREPASO, que suplanta al de Menen se vio envuelto en esa vorágine. Por incapacidad propia y por la insistencia en mantener el modelo económico, nunca pudo superar los problemas estructurales: desocupación, pobreza, exclusión social. La crisis de representación política y el deterioro de la figura presidencial alimentaron la imagen de un modelo político decadente que perdía consenso social casi a diario. Las jornadas de diciembre de 2001, las protestas y la represión oficial marcaron el paroxismo de un proceso de crisis social y política muy profunda para la Argentina.

La protesta social que adoptó diferentes formas, muchas de las cuales hemos intentado explicar más arriba, no logró, sin embargo, traducirse en colectivo unificado. Como lo entiende Retamozo en su trabajo, la protesta social no devino en sujeto político, es decir, la protesta ganó las calles, pero en forma desarticulada, y esto marcó un límite para incorporar la lógica del movimiento político. Es indudable que las jornadas de diciembre generaron condiciones para crear espacios de repolitización del espacio público, con el desarrollo de asambleas que se formaron bajo la consigna "Que se vayan todos". En ese sentido dejaron una impronta en el imaginario social más allá de que su influencia sólo logró superar el tiempo de la coyuntura, aunque algunas siguieron operando durante un tiempo más. Logrando tener cierta influencia en nuevas jornadas de protesta en el año 2002, una vez instalado el gobierno provisional de Eduardo Duhalde.

Durante el interregno Duhalde los movimientos sociales optaron por distintas estrategias de acción social y política frente al estado. Algunas aceptaron incorporarse a la propuesta del gobierno de crear el plan jefes y jefas de hogar desocupado que supuso un ingreso menor para paliar los efectos de la crisis. 
Otras como el caso de la agrupación Aníbal Verón o el Polo Obrero redoblaron su actitud de enfrentamiento con nuevas movilizaciones callejeras. En una de estos cortes de rutas, el 26 de junio de 2002 fueron asesinados dos jóvenes manifestantes Darío Santillán y Maximiliano Kosteky por miembros de la policía de la provincia de Buenos Aires. Como respuesta a la muerte de estos militantes se produjo una nueva ola de protestas que promovió la articulación de los diferentes sectores, la CTA, los organismos de derechos humanos, las Asambleas Barriales y el movimiento estudiantil que forzaron a una convocatoria a elecciones presidenciales para marzo de 2003.

A partir de 2003 y luego de elecciones en las cuales Néstor Kirchner triunfa con el 22 por ciento de los votos, las expectativas que se abren son muchas. El Gobierno de Kirchner al asumir elaboró un discurso que apuntó a recomponer la política como articuladora entre estado y sociedad. Las premisas fueron garantizar el rol del estado como asignador de recursos sociales y permitir la gobernabilidad recomponiendo las bases del sistema representativo, tan desgastado con la crisis política. De esa manera encontró una forma de articular las demandas de algunos movimientos sociales que quedaron adheridos al proyecto que elaboraba el ejecutivo, a través de vehiculizar un proyecto político antineoliberal, de raíz "nacional-popular". De esta manera se logró atraer a algunos movimientos a la lógica política gubernamental y crear otros afines al proyecto kirchnerista. Sin embargo, algunos sectores del movimiento de desocupados (por ejemplo la nueva organización Darío Santillán) o del sector sindical (una fracción de la CTA) mantuvieron una postura crítica frente al gobierno kirchnerista.

Es necesario decir que el gobierno kirchnerista ha establecido un conjunto de políticas públicas que permitieron reconfigurar el campo de las relaciones sociales. Se ha establecido una serie de medidas que apuntaron a revitalizar el funcionamiento del mercado de trabajo y la recuperación de los índices de empleo.

De este modo el gobierno intentó responder a la demanda del movimiento de desocupados promoviendo el trabajo registrado y organizando la fuerza laboral del movimiento por medio de las cooperativas, especialmente gestionadas por organizaciones afines al gobierno.

Ante la demanda del movimiento de empresas recuperadas ya en 2002 se había modificado el artículo 190 de la Ley de Concursos y Quiebra, que contempla el pedido por parte de los trabajadores reunidos en cooperativas para la continuidad de la actividad laboral. En 2004 el Ministerio de Trabajo y Seguridad Social puso en funcionamiento el Programa de Trabajo Autogestionado y firmó convenios con varias de las empresas recuperadas. Silvia L. Rodríguez afirma que, el gobierno de Kirchner colaboró en darles una estabilidad jurídica, que les faltaba. En la actualidad se puede hablar de la existencia de unas 270 fábricas recuperadas en todo el país, lo que le otorga al movimiento mucho mayor 
estabilidad y legitimidad en su acción, basada en una forma de organización horizontal en la toma de decisiones. Además lograron cierto formato jurídico para la continuidad de su funcionamiento sostenido en el apoyo estatal. A su vez constituyen al día de hoy, una forma embrionaria, donde la fuerza de trabajo avanza sobre la propiedad de los medios de producción.

El gobierno de Kirchner ha mantenido en estos años una activa política frente a la demanda de los organismos de derechos humanos respecto a los crímenes cometidos durante la dictadura militar. Una forma fue apoyar la derogación de las Leyes de Obediencia Debida y Punto Final, así como la recuperación del predio de la Escuela de Mecánica de la Armada (ESMA) donde funcionó un centro clandestino de detención. Lo que le permitió el apoyo de notables personalidades del campo de los derechos humanos como la presidenta de Abuelas Estela de Carlotto y las referentes de las Madres de Plaza de Mayo en sus dos vertientes Hebe de Bonafini y Taty Almeida.

En esta reseña tenemos que incluir en la nómina de nuevos movimientos sociales a los que han surgido en defensa del medio ambiente, como los casos de los conformados en repudio a los daños producidos por el desarrollo de ciertos modelos productivos en diversos lugares del país. Uno de los casos fue el movimiento de protesta frente al avance de la minería a cielo abierto que tuvo su epicentro en el pueblo de Esquel $^{2}$ en el nordeste de la provincia de Chubut en el año 2003, así como en la provincia de Río Negro en el año 2005. Estos episodios se han venido desarrollando en otros puntos del país. En enero de 2012 el rechazo a la megaminería dijo presente en cuatro provincias: Chubut, La Rioja, Catamarca y Río Negro donde se produjeron movilizaciones de repudio a la actividad extractiva, que en las cuatro provincias contaba con apoyo de los gobiernos provinciales.

Otro ejemplo de rechazo a los modelos de producción y a sus efectos contaminantes lo tenemos respecto a la contaminación del Río Uruguay. Allí las asambleas actuaron en repudio a las empresas papeleras que se habían instalado en las costas uruguayas, más precisamente en la ciudad de Fray Bentos. El principal foco de protestas se ubicó en la ciudad de Gualeguaychú (Entre Ríos) y su forma de acción colectiva fue el prolongado corte del paso Argentina-Uruguay. Estos cortes profusamente difundidos a nivel de los medios

2. Esquel marcó un quiebre respecto de la acción que las comunidades tomaron frente al avance de empresas mineras. En 2002 se instaló la compañía canadiense Meridian Gold, que pretendía explotar el proyecto Cordón de Esquel para extraer oro y plata a sólo seis kilómetros de la ciudad. Movilizaciones, jornadas informativas y un histórico plebiscito rechazaron la megaminería. También lograron la sanción de la Ley 5001, que prohíbe la actividad en la provincia. A pesar de la ley, las empresas extranjeras siguieron explorando el centro de la provincia, con el fin de extraer plomo y plata (proyecto llamado Navidad). Las comunidades indígenas (mapuche-tehuelche), que cuentan con leyes específicas sobre el territorio, rechazan las actividades mineras, y han participado de las movilizaciones junto a asambleas ambientales de Trevelin, Puerto Madryn y Río Mayo, localidades vecinas a Esquel. 
de comunicación permitieron la visibilización del reclamo y la intervención de los gobiernos de Argentina y Uruguay, para intentar resolver el problema, a través de la búsqueda de acuerdos bilaterales. La duración e intensidad que adquirió el conflicto, obligó al gobierno argentino a llevar esta cuestión a los tribunales internacionales, con el resultado de que una de las empresas involucradas en las denuncias de los asambleístas desistió de ubicarse en el país vecino.

Estos movimientos en defensa del medio ambiente, incluyen en sus demandas una serie de medidas de protesta contra el modelo productivo extractivista, concebido en base a los denominados agronegocios, a la renta minera y a la explotación de yacimientos no convencionales.

Un balance general de la actuación de las organizaciones ambientalistas que actúan en contra de la minería a cielo abierto, permite decir que sus logros han sido parciales, y a veces sólo acotados al ámbito local, sin lograr una articulación a nivel nacional, lo que en cierta forma marca las limitaciones de su accionar. De esa manera fue posible que en algunas zonas, donde se realizaba la minería a cielo abierto se logró poner freno a la actividad de las empresas; aunque otras, incluso, siguieron operando en algunos casos, con algunas modificaciones en las formas de explotación. Pero no ocurrió lo mismo, en aquellas provincias donde la renta minera es prioridad y es sostenida por las políticas oficiales, que actúan de escudo frente a las demandas de los ambientalistas.

Dentro de este contexto, y frente a la aparición de otras formas de explotación de recursos naturales se han abierto nuevos interrogantes, con respecto al posible daño irreversible al entorno natural que su actividad supone. Una de ellas es el método de fractura (yacimientos no convencionales), propiciado por un grupo de empresas que esperan aprovechar las reservas de gas shale. La reacción a este tipo de explotación ha tenido avances limitados, debido a que solo se prohibió en determinadas ciudades, sin vislumbrarse cambios a nivel nacional.

\section{La política kirchnerista y sus consecuencias para el movimiento social}

A partir del periodo iniciado en 2003, los sucesivos gobiernos de Néstor Kirchner y Cristina Fernández de Kirchner, han puesto en vigencia una serie de medidas en políticas públicas, que en cierta forma han sido la respuesta a algunas de las demandas de los movimientos sociales. El proyecto político kirchnerista, de esa manera, junto con la inclusión en el gobierno de algunos de sus representantes y la firme decisión de no reprimir la protesta social, fue conduciendo las riendas del proceso social desde el conflicto pleno hacia "aguas mas calmas", lo que permitió una merma en la conflictividad social.

Por otro lado, con la aplicación de un modelo productivo que permitió recuperar la actividad económica, se logró una importante reactivación del empleo (ya sea precario o estable) lo que le dio mayor participación al sector sindical a través de la vigencia de las paritarias, que de esa forma toma nuevamente fuerza 
como espacio de negociación. Al mismo tiempo, va perdiendo significación el movimiento piquetero, al disminuir su capacidad de movilización y de enfrentamiento con el Estado.

Ahora bien, el gobierno kirchnerista buscó restablecer el lugar central del Estado articulando un modelo de acumulación y un régimen político, que le permitió encontrar respuestas institucionales para absorber las demandas, incorporando las que provenían de los movimientos sociales. El Estado se transformó en un "canal" por donde circulaban y se expresaban las demandas.

Según Retamozo, el kirchnerismo procuró interpelar a las organizaciones sociales no por medio de la búsqueda de la disolución de los movimientos sino por medio de la recanalización de los modos de participación. Los movimientos sociales kirchneristas asumieron tanto formas más institucionalizadas (varios cuadros pasaron a ser funcionarios) y también incorporaron una variedad de formas políticas novedosas para cuya concreción fueron claves los activistas de los movimientos sociales, especialmente los jóvenes. De este modo un conjunto de organizaciones evaluaron la posibilidad de formar parte del "movimiento nacional-popular" bajo la conducción de Néstor Kirchner y actualmente de Cristina F. de Kirchner aunque esto signifique resignar grados de autonomía.

Para poder completar este cuadro de interpretación de los movimientos sociales es necesario decir que, así como hemos visto que este gobierno fue articulando demandas a favor de la búsqueda de consensos con algunas organizaciones, las protestas que otras han protagonizado ha propiciado el surgimiento de un nuevo campo de confrontación y antagonismo contra el Estado. El surgimiento y consolidación en estos últimos 10 años del proyecto kirchnerista ha provocado la constitución de un campo de oposición en el que se encuentran demandas de agrupaciones de izquierda, así como de un nuevo bloque de fuerzas conservadoras, denominadas por algunos analistas cómo de una "nueva derecha” argentina.

Entre las primeras podemos destacar aquellas que exigen cambios más profundos en la distribución del ingreso (sectores de la CTA, CGT Moyanista, sindicalismo liderado por organizaciones de izquierda -Partido Obrero y Partido de los Trabajadores por el Socialismo-), o también organizaciones de desocupados y partidos y sindicatos de izquierda y aquellas que demandan la finalización del modelo económico por considerarlo basado en la depredación de los recursos naturales. Muchas de ellas critican el carácter imperialista y extranjerizante del modelo productivo bajo explotación de grandes capitales nacionales y extranjeros. Entre ellas, podemos citar, entre otros, al Movimiento campesino de Santiago del Estero, MOCASE, o al Movimiento campesino de Formosa, MOCAFOR, ambos nucleando demandas por la tierra o derechos campesinos e indígenas. Estas protestas enfrentan el avance del monocultivo de soja y la deforestación propiciada por el avance de la superficie sembrada en detrimento del pequeño campesino y de las comunidades indígenas. 
Una nueva forma de oposición: Los movimientos sociales conservadores Por otro parte también se oponen al kirchnerismo sectores y organizaciones que podemos ubicar en los emergentes de una "nueva derecha argentina". Que si bien no presentan carácter orgánico partidario, reciben el apoyo de un sector social acomodado y la difusión de su accionar y demandas de importantes medios de comunicación masiva del país.

Es a partir del año 2008, en un contexto general de reducción de los niveles de crecimiento de la economía argentina, donde se inicia un proceso de protestas protagonizadas por sectores del empresariado rural, a través de las cuatro entidades agropecuarias que los nuclea. El principal foco del reclamo fue su oposición a la elevación de la alícuota a las retenciones para la exportación de soja, girasol, maíz y trigo (Resolución Nro. 125/08). Este conflicto que duró varios meses fue profusamente difundido por los medios de comunicación y promovió una dura lucha política y mediática. Al final el gobierno no pudo aplicar la medida, que había sido enviada al Congreso Nacional, y rechazada para su aplicación. Los empresarios del sector adquirieron mucha visibilidad mediática lo que les permitió desarrollar una unidad de acción que nunca antes habían tenido.

Por otra parte, apareció en la escena social un movimiento constituido para bregar por la "seguridad ciudadana", cuya principal figura fue Juan Carlos Blumberg, que en 2004 organizó marchas con decenas de miles de asistentes y solicitaba el endurecimiento de las penas, la baja de la edad para establecer la imputabilidad de los menores, mayores atribuciones para la policía, entre otras medidas. Otros grupos opositores de esa "nueva derecha" son aquellas organizaciones que reivindican la actuación de los militares en la última dictadura militar y solicitan el fin de los juicios por lo que denominan una persecución política. Mantienen su postura de condenar a los "terroristas de ayer", incluyendo en su demanda a funcionarios del actual gobierno.

\section{A modo de cierre}

Estos movimientos que acabamos de describir de alguna forma son el producto de la creación de nuevas identidades colectivas, constituidas al calor del rechazo o resistencia a la aplicación de políticas de desestructuración social gestadas por el neoliberalismo desde los años'90. Son también formas de organización que retoman cierta tradición social, pero que podemos caracterizar como novedosas en este contexto, sobre todo por llevar adelante reivindicaciones de inclusión social, y transformación del Estado, pero sin cuestionar la existencia de la nación como marco jurídico-político.

En definitiva es posible afirmar que el advenimiento de esta "nueva ciudadanía”, que buscaba formas de expresión por otros canales no convencionales, es la consecuencia de un proceso de desinstitucionalización que se profundizó en los años 90, provocando el debilitamiento de los lazos organizacionales y de 
las identidades adscriptas dentro de formas institucionalizadas. También es una crisis de la "voluntad política" de cambio que han experimentado algunas organizaciones populares (partidos políticos tradicionales como la UCR y el PJ) que perdieron gran parte de su credibilidad y legitimidad por su forma de actuación durante la década. Ante esta crisis los discursos de los movimientos sociales, han surgido como alternativa tanto a la intervención estatal (también en crisis) como a las regulaciones públicas, que a su vez tiene su correlato con la idea de sustitución de la política por la administración gubernamental a través de los tecnócratas, que habían adquirido poder durante los año '90.Digamos, la tecnocracia sustituyó a la política y puso en tela de juicio la relación entre representantes y representados.

Esta reacción contra los partidos políticos tradicionales y contra la tecnocracia, desde una protesta social que tuvo su momento culminante en los acontecimientos de diciembre de 2001, fue capaz de articular una nuevo vínculo entre política y sociedad civil y ha dejado una marca, una impronta en la memoria social y una forma de acción social (corte rutas, piquetes, asambleas) que ha alimentado el repertorio de la forma que asume la protesta social y la resistencia, particularmente respecto a las políticas estatales.

Sin embargo, el balance de los resultados logrados por los diferentes movimientos sociales muestra elementos contrapuestos. Por un lado con el planteo del "que se vayan todos" de las asambleas barriales, que propiciaba el fin de un sistema político basado en la representación, se logró cierto desplazamiento de algunas figuras de la política tradicional, pero el sistema de representación no se ha modificado sustancialmente. Aunque es necesario reconocer que a partir del 2001 mucho ha cambiado en la relación entre política y sociedad en la Argentina. En los últimos años la política vuelve a ocupar un lugar central en la escena, al ser rehabilitada como espacio de negociación-confrontación y como herramienta de transformación social. La pregunta que es necesario hacerse es: ¿Cuál ha sido el papel de los movimientos sociales para la recuperación de la política?

Evidentemente el surgimiento de estas nuevas formas de acción colectiva ha tenido un impacto formidable, al actuar como dinamizadoras de la práctica política. Demostrando como, a través del recurso de la actuación en ámbitos públicos, no sólo fue posible su visibilización, si no la generación de un fuerte cuestionamiento al sistema de representación política, sobre la que se basa el modelo demo-liberal de la democracia argentina. Su principal fortaleza ha sido el desarrollo de la capacidad de resistencia y su potencialidad como factor contestatario del orden social, aunque quizás, podría decirse ha demostrado cierta debilidad para transformarse en una opción política articulada.

El proyecto político del kirchnerismo se fue desarrollando bajo esas condiciones de oportunidad, vehiculizando el conflicto social y la energía que la protesta de los 
movimientos sociales provocaba. Creando lazos institucionales que permitieron tejer una estructura política basa en la inclusión de muchas de las demandas que habían encontrado visibilidad a partir de la acción de los nuevos movimientos. Esto le permitió reconducir la política argentina y direccionar el conflicto reubicando al Estado en un papel central en la asignación de recursos sociales demandados. El kirchnerismo, a través de un discurso basado en las premisas del "proyecto nacional y popular", tan caro al pensamiento tributario de la tradición peronista, pudo establecer un nexo más sólido entre política y sociedad.

Esta situación marca un límite respecto a la situación actual de los movimientos sociales. Los movimientos sociales argentinos, han demostrado, como hemos argumentado, el desarrollo de una identidad muy rica como fuerza contestataria. También como fuerza creativa, a partir del desarrollo de experiencias basadas en la autogestión, autoorganización, incluso con formas embrionarias de autogobierno. Todavía resta saber cuál es su verdadera capacidad para convertirse en fuerza política capaz de disputar instancias de poder, en un escenario dominado por el kirchnerismo.

También es necesario decir que algunos movimientos sociales siguen estando presentes en la dinámica política, manteniendo lógicas de confrontación con el estado, no ligadas al modelo kirchnerista, intentan defender ciertas formas de autonomía, como el caso del Frente Popular Darío Santillán que mantiene ciertas formas de organización distanciadas del influjo oficial.

Para cerrar este cuadro, es necesario destacar el accionar de una "nueva derecha conservadora" que desde 2008 viene ocupando un espacio mayor como fuerza opositora al proyecto kirchnerista. Su fuerza radica en el uso de ciertos aparatos discursivos que encuentran canales de expresión tanto en la prensa(también opositora) como incluso en algunos partidos políticos y hasta en la propia Iglesia Católica. Estas expresiones han demostrado cierta virulencia en la acción y también han encontrado formas de expresión ocupando el espacio público a través de resonantes manifestaciones callejeras.

Finalmente es necesario reflexionar sobre el potencial liberador y la promesa emancipatoria que los nuevos movimientos sociales promueven a partir de su emergencia. Tanto los que están dentro como fuera del gobierno en la Argentina actual, tienen un lugar clave en la disputa ideológica y en la lucha política, y muestran la capacidad de constituir fuerzas con una energía transformadora del orden social.

Esta capacidad transformadora se inscribe en un proceso que excede el campo de acción social de la Argentina, y presupone una proyección hacia otras experiencias similares existentes a nivel de nuestro continente. El tiempo dirá los alcances y limitaciones de esas proyecciones. 


\section{Bibliografía}

Retamozo, Martín. Movimientos sociales, política y hegemonía en Argentina, Polis [En línea], 28 | 2011. Publicado el 13 abril 2012, consultado el 01 marzo 2015. URL: http://polis.revues.org/1249 ; DOI: 10.4000/ polis.1249.

Rodríguez, Silvia Laura. [en línea] Los movimientos sociales en la Argentina a partir de la década del 90. Ponencia presentada en: “XVIII Encuentro Nacional de Economía Política” organizado por la Sociedad Brasilera de Economía Política -SEP, año 2013. Licenciada en Historia UBA, Argentina e integrante del CEMOP.

Klachko, Paula. La conflictividad social en la Argentina de los'90: el caso de las localidades de Cutral Có y Plaza Huincul (1996-1997) en: Crisis y conflicto en el capitalismo latinoamericano, Bettina Levy ( comp.) CLACSO, 2002.

Pacheco, Mariano. De Cutral Có a Puente Pueyrredón. Una genealogía de los Movimientos sociales, Buenos Aires. Editorial El Colectivo, 2008.

Svampa, Maristella. Movimientos sociales en la Argentina de hoy. Piquetes y Asambleas. Tres estudios de casos. Equipo de Trabajo: Damián Corral, Mariana Barattini y Marina García [en línea] CEDES, Argentina, Diciembre de 2002.

Svampa, Maristella. Movimientos piqueteros, 2001-2011. Del centro político al retorno al barrio. Le Monde Diplomatique, publicación mensual núm.150, año XIII. Diciembre 2011.

Solana, Pablo. 2001-2011: las dimensiones de la rebelión al calor de la experiencia de los movimientos barrales y de trabajador@ desocupad@s. Revista Herramienta $\mathrm{n}^{\circ} 46$.

Palomino, Héctor. Las experiencias actuales de autogestión en Argentina, Nueva Sociedad, núm. 184. Marzo-Abril, 2003, 115-128. 